\title{
Evaluations of Hydrogen Permeation on Ni-SCYb Nano-Composites Membrane by Sol-Gel Methods
}

\author{
Min Gyeom Kim and Tae Whan Hong* \\ Department of Material Science and Engineering/Research Center for Sustaninable Eco-Devices and Materials(ReSEM), \\ Korea National University of Transportation, Chungju 27469, Republic of Korea
}

\begin{abstract}
Industrially meaningful hydrogen production process from mixture or syngas certainly must have a cooling process, which is typically pressure swing adsorption (PSA). However, the PSA process involves an exothermic reaction during adsorption. Recently, hydrogen separation research has been in progress in order to develop a cooling process to minimize or eliminate high temperature. Proton conducting ceramics with high proton conductivity, due to their many potential applications, are used in fuel cells and in the separation of hydrogen. Especially, the proton conducting ceramic $\mathrm{Sr}_{1.0} \mathrm{Ce}_{0.95} \mathrm{Yb}_{0.05} \mathrm{O}_{3-\delta}(\mathrm{SCYb})$ has a relatively large surface area and good chemical stability at high temperature. Therefore, $\mathrm{SCYb}$ composites with nanosize particles are expected to have a good influence on the Knudsen diffusion mechanism. In this work, in order to achieve effective hydrogen separation at high temperature, Ni-SCYb nano-composites were prepared by sol-gel process and ball-milling at low temperatures. Synthesized Ni-SCYb nano-composites were characterized by SEM(FE-SEM, JEOL7500F), XRD(Bruker D8 Focus) and BET(BEL SOROP-minilI). The hydrogen permeation properties of $\mathrm{Ni}-\mathrm{SCYb}$ membrane were measured by Sievert's type hydrogen permeation membrane equipment. Through BET analysis, Ni-SCYb composite powders were measured and specific surface area was found to be $0.5399 \mathrm{~m}^{2} / \mathrm{g}$. Hydrogen permeability of Ni-SCYb was found to be $5.77 \times 10^{-7} \mathrm{~mol} / \mathrm{ms} \mathrm{Pa}^{1 / 2}$ at $973 \mathrm{~K}$ under $0.3 \mathrm{MPa}$.
\end{abstract}

(Received December 14, 2017; Accepted February 14, 2018)

Keywords: hydrogen permeation, proton conducting ceramics, $\mathrm{Ni}-\mathrm{Sr}_{1.0} \mathrm{Ce}_{0.95} \mathrm{Yb}_{0.05} \mathrm{O}_{3-\delta}$ nano composites, sol-gel process, cermet membrane

\section{INTRODUCTION}

Recently, according to the urgent issues of energy security caused by the exhaustion of fossil fuels, hydrogen, which has a high energy density, has been in the spotlight as a future source of energy $[1,2]$. Because of its clean energy mediation and because it is a ho-discharge energy sourse, hydrogen is a very promising solution that is expected to contribute to solving envirommental problems and volunteer at the same time [3]. Hydrogen that occurs in the process of hydrogen or common industrial processes is mixed with carbon monoxide, carbon

*Corresponding Author: Tae Whan Hong [Tel: +82-43-841-5388, E-mail: twhong@ut.ac.kr] Copyright (C) The Korean Institute of Metals and Materials dioxide, oxygen, nitrogen, water, methane, etc. In order to obtain high concentrations of hydrogen, hydrogen separation technology is necessary. With the increasing demand for hydrogen, hydrogen separation technology of low cost and high efficiency is desperately needed in preparation for the hydrogen economy [3,4]. Many receut experimental studies have focused on the processing of nano-crystalline materials, characterization of their microstructure and determination of material properties [6]. The typical hydrogen separation technologies are the Pressure Swing Adsorption (PSA), Thermal Swing Adsorption (TSA), Cryogenic Distillation, Getter, and Membrane processes. Among them, hydrogen separation technology using membranes is being evaluated as the most promising technology. A Pd-based hydrogen membrane, which has high hydrogen permeability 
and selectivity, has been studied since the early 1990s. However, it has problems that need be solved for commercialization, such as support stability problems, defect generation, membrane reproducibility problems, etc. [5]. To overcome these problems, a cermet membrane created by combining the advantages of metal and ceramic has been studied [6]. Since nickel can also permeate hydrogen, the contribution from the $\mathrm{Ni}$ path to the total hydrogen permeation needs to be taken into account [7]. Gas separation technology utilizing a composite conductive oxide membrane is a new coal-based power generation technology and, in separating hydrogen gas from the coal gasification process, this is are essential technology [8]. The oxide of the perovskite structure represents the ion conductivity; the composite conductivity has been studied and found to be $\mathrm{BaCe}_{1-\mathrm{x}} \mathrm{Y}_{\mathrm{x}} \mathrm{O}_{3-\delta}, \mathrm{SrCe}_{1-\mathrm{x}} \mathrm{Y}_{\mathrm{x}} \mathrm{O}_{3-\delta}$, etc. [9]. In the perovskite oxide, the movement mechanism of the cation is known as Grotthuss type (free proton migration) [10]. Hydrogen separation processes using dense ceramic membranes with a perovskite structure are known to start with the oxidation of hydrogen gas at the membrane surface. The generated cations and electrons are mixed in the membrane lattice. Then, they diffuse to the surface of the reduction area. In this process, high purity hydrogen gas is generated [11]. In the defect reaction, improvement of the conductivity of the cation of the additive is related to the generation of oxygen vacancies in the solid state. Also, each of the oxygen vacancies will lead to the production of two cations in the crystal structure. Nickel is an electronic conductor and plays a role as metal support. In this study, Ni-SCYb composite membranes are successfully fabricated by hot press sintering using $\mathrm{Ni}-\mathrm{SCYb}$ powders prepared by the sol-gel method and ball-milling under various conditions. Also, to secure only hydrogen and isotopes from the mixture gas, which contained gas harmful to the environment, the study evaluated the permeability characteristics of hydrogen through the $\mathrm{Ni}-\mathrm{SCYb}$ cermet membrane. By doing so, it tried to provide a next generation green energy technology than is both economically feasible and low in pollution.

\section{EXPERIMENTAL DETAILS}

\subsection{Synthesis of SCYb composites}

To obtain $\mathrm{SCYb}$ composite, $\operatorname{Sr}\left(\mathrm{NO}_{3}\right)_{2}[\geq 99.0 \%$, Sigma], $\mathrm{Ce}\left(\mathrm{NO}_{3}\right)_{3} \cdot 6 \mathrm{H}_{2} \mathrm{O}\left[99 \%\right.$, Sigma], $\mathrm{Yb}\left(\mathrm{NO}_{3}\right)_{3}[99.9 \%$, Sigma], citric acid[ $\geq 99.5 \%$, Sigma], and ammonia [Sigma] were used as received. $\mathrm{Sr}\left(\mathrm{NO}_{3}\right)_{2}, \mathrm{Ce}\left(\mathrm{NO}_{3}\right)_{3}$. $6 \mathrm{H}_{2} \mathrm{O}$ and $\mathrm{Yb}\left(\mathrm{NO}_{3}\right)_{3}$ were dissolved in deionized water, and then the solution was slowly dropped into citric acid. Using ammonia, the $\mathrm{pH}$ value of the mixed solution was adjusted to 8 . The resulting solution was stirred and heated at $343 \mathrm{~K}$ until a viscous liquid was obtained; it was then dried at $343 \mathrm{~K}$ and 423 $\mathrm{K}$. The citrate precursors were calcined at $623 \mathrm{~K}$ and $1373 \mathrm{~K}$ in air for $5 \mathrm{~h}$ [12].

\subsection{Preparation of Ni-SCYb composites membrane}

$\mathrm{Ni}-\mathrm{SCYb}$ composites was prepared by using ball milling to mix pure nickel powder (High Purity Chemicals, purity $99.9 \%$ and up) and $50 \mathrm{wt} \% \mathrm{SCYb}$ composite powder.[13] To mold a hydrogen separation membrane of disk type, the obtained composite powder was molded into disk form using a press at a pressure of $40 \mathrm{MPa}$. To improve the density of the disk type membrane through pressure and heat treatment, Hot Press Sintering (HPS) was performed for $3 \mathrm{~h}$ at $1473 \mathrm{~K}$ under 2 tons.

\subsection{Characterization of composites synthesized} and composites membrane

$\mathrm{X}$-ray diffraction analysis using $\mathrm{Cu} \mathrm{K} \alpha$ radiation (D8 Advance, Bruker Corp.), a Brunauer Emmet Teller surface analyzer (BET, BEL Sorp mini II, BEL Co.) and a scanning electron microscope (SEM, Quanta-400, FEI Corp.) have been used to investigate the crystal phase of the powder, the surface structure and the microstructure of the $\mathrm{SCYb}$ and $\mathrm{Ni}-\mathrm{SCYb}$ composites. For evaluation of the hydrogen permeation of the $\mathrm{Ni}$ $\mathrm{SCYb}$ composite membrane, Fig. 1 shows the 

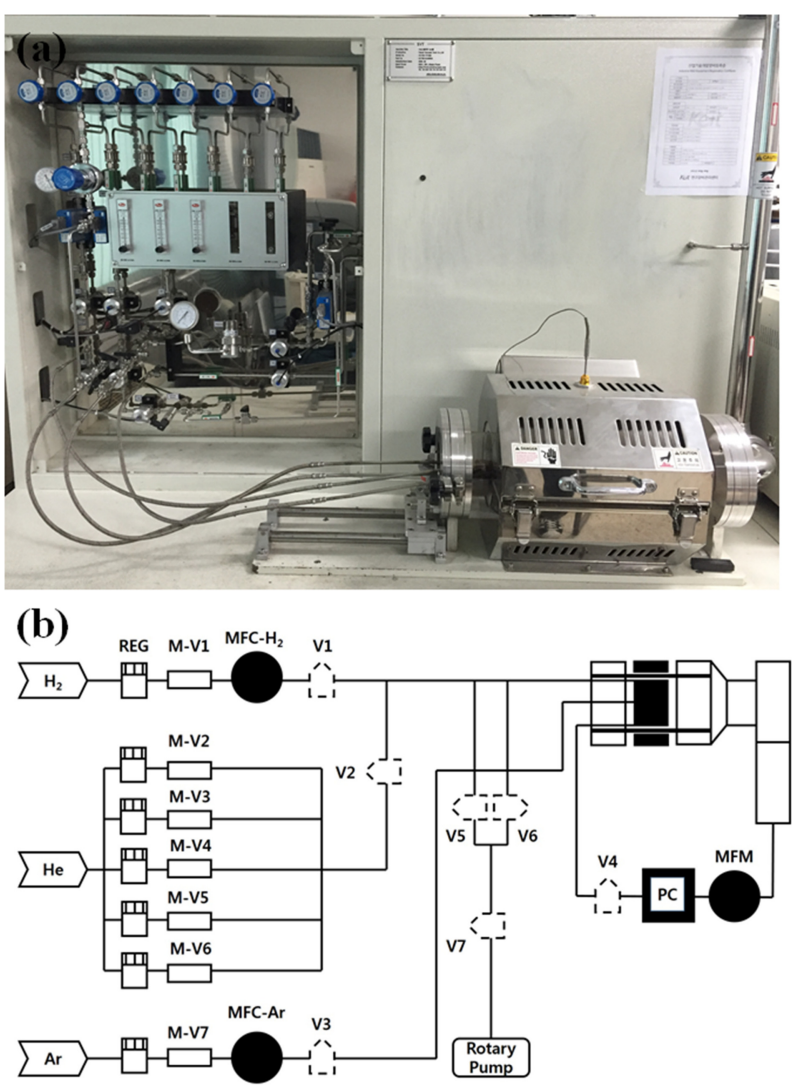

Fig. 1. (a) The apparatus for gas permeation measurement and (b the schematic diagram of apparatus.

hydrogen permeability at various temperatures and hydrogen pressures; data were obtained using a Sievert's-type hydrogen permeation apparatus (RT-973 $\mathrm{K}, 0.1-0.3 \mathrm{MPa}$ ).

\section{RESULTS AND DISCUSSION}

$\mathrm{SCYb}$ composite under a variety of conditions was analyzed by XRD to determine the crystal structure. Figure 2 provides XRD patterns of the (a) $\mathrm{SCYb}$ dried at $423 \mathrm{~K}$, (b) $\mathrm{SCYb}$ burned at $623 \mathrm{~K}$, (c) $\mathrm{SCYb}$ calcined at $1373 \mathrm{~K}$ and (d) Ni-SCYb composites. In Fig. 2(a) and (b), they can be seen to be composed of carbonates and oxide, such as $\mathrm{Sr}_{2}\left(\mathrm{CeO}_{4}\right), \mathrm{CeO}_{2}, \mathrm{Sr}$ and $\mathrm{SrCO}_{3}$, with peaks due to $\mathrm{SCYb}$ composites in the $423 \mathrm{~K}$ and $623 \mathrm{~K}$ unstable states. However, when samples were calcined at $1373 \mathrm{~K}, \mathrm{Sr}_{2}\left(\mathrm{CeO}_{4}\right), \mathrm{CeO}_{2}$ and $\mathrm{Sr}, \mathrm{SrCO}_{3}$ peaks disappeared and only the perovskite

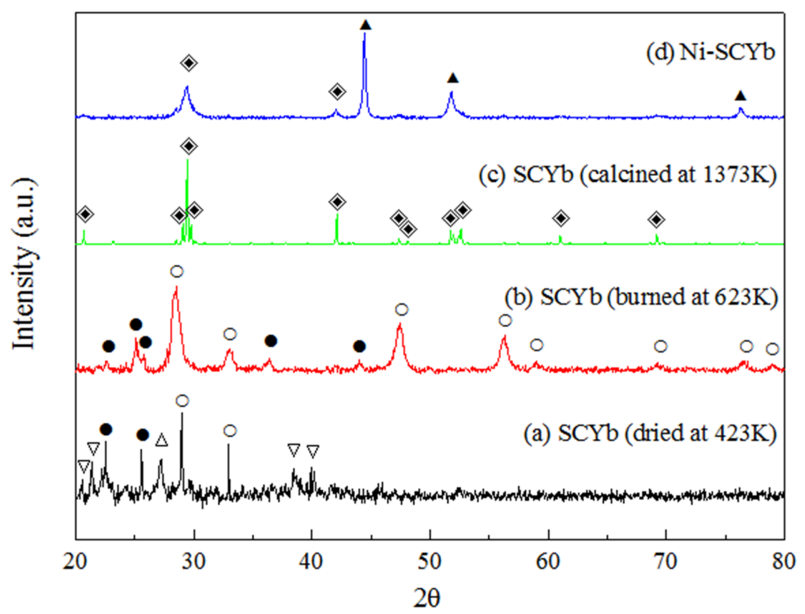

Fig. 2. XRD pattern of the $\mathrm{SCYb}$ at $423 \mathrm{~K}, 623 \mathrm{~K}, 1373 \mathrm{~K}$, NiSCYb composites $\left(\nabla ; \mathrm{Sr}\left(\mathrm{CeO}_{4}\right), \triangle ; \mathrm{Sr}, \bullet ; \mathrm{CeO}_{2}, \circ ; \mathrm{SrCO}_{3}, \diamond ; \mathrm{SCYb}\right.$, $\boldsymbol{\Delta} ; \mathrm{Ni})$

phase of $\mathrm{SCYb}$ is indicated sharply. In Fig. 2(d), the $\mathrm{Ni}$ phase and perovskite phase of $\mathrm{SCYb}$ were observed. Figure 3 shows an SEM image of the $\mathrm{SCYb}$ composites under a variety of conditions. Figure $3(\mathrm{a}) \sim(\mathrm{c})$ is $\mathrm{SCYb}$ at $423 \mathrm{~K}, 623 \mathrm{~K}$ and $1373 \mathrm{~K}$, (d) shows the Ni-SCYb composites, and (e) (f) are before and after samples of hydrogen permeation evaluation on the $\mathrm{xNi}-\mathrm{SCYb}$ composites membrane. Figure 3(a) and (b) do not show clear boundaries of particles: numerous nano particles were bonded together because of the moisture remaining in the powder. Figure 3(c) shows that $\mathrm{SCYb}$ calcined at $1373 \mathrm{~K}$ had particles that were clear and of elongated shape. Fig. 3(d) shows Ni-SCYb, which was fabricated using $\mathrm{SCYb}$ with the addition of nickel powder as a catalyst and support to prevent embrittlement. Figure 3(e) and (f) shows the surface of the membrane. In the Fig. 3(e), the membrane of disk type seemed very flat, smooth and dense, in contrast to the surface shown in Fig. 3(f), on which small holes occurred and the surface became uneven. This result is expected to be due to the permeation of hydrogen, as well as to the various temperature and pressure conditions.

Table 1 shows BET results for specific surface area, total pore volume and average pore diameter of samples. $\mathrm{SCYb}$ at $623 \mathrm{~K}$ had the highest specific surface area; specific surface area can be found to be 

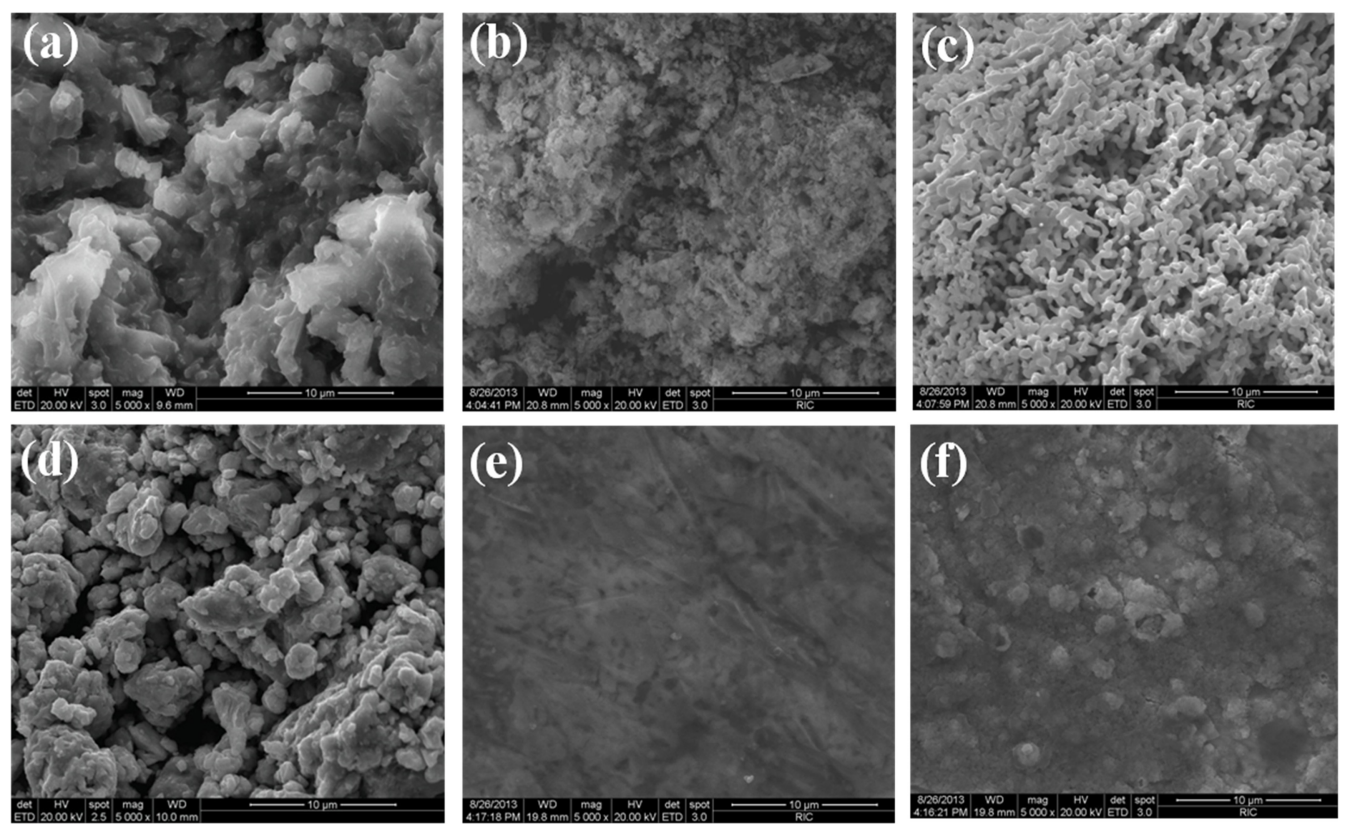

Fig. 3. SEM images of the (a) SCYb at $423 \mathrm{~K}$, (b) SCYb at $623 \mathrm{~K}$, (c) SCYb at $1373 \mathrm{~K}$, (d) Ni-SCYb, (e) Ni-SCYb membrane and (f) Ni$\mathrm{SCYb}$ composites membrane of after hydrogen permeation.

Table I. Surface area, pore volume, and average pore diameter of the samples.

\begin{tabular}{cccc}
\hline Samples & $\mathrm{a}_{\mathrm{s}}, \mathrm{BET}\left(\mathrm{m}^{2} \mathrm{~g}^{-1}\right)$ & $\begin{array}{c}\text { Total pore } \\
\text { volume }\left(\mathrm{cm}^{3} \mathrm{~g}^{-1}\right)\end{array}$ & $\begin{array}{c}\text { Average pore } \\
\text { diameter }(\mathrm{nm})\end{array}$ \\
\hline $\mathrm{SCYb} 423 \mathrm{~K}$ & 0.91295 & 0.0015136 & 6.6317 \\
\hline $\mathrm{SCYb} \mathrm{623} \mathrm{K}$ & 15.682 & 0.025248 & 6.4399 \\
\hline $\mathrm{SCYb} \mathrm{137} \mathrm{3K}$ & 2.0186 & 0.0030301 & 6.0044 \\
\hline $\mathrm{Ni}-\mathrm{SCYb}$ & 0.53987 & 0.0010517 & 7.7925 \\
\hline $\begin{array}{c}\mathrm{Ni}-\mathrm{SCYb} \\
\text { membrane }\end{array}$ & 0.048885 & 0.000097904 & 8.011 \\
\hline $\begin{array}{c}\text { After hydrogen } \\
\text { permeation }\end{array}$ & 0.021904 & 0.0094225 & 17.206 \\
\hline
\end{tabular}

significantly reduced by grain growth caused by high temperature and the addition of nickel. Also, pore volume was independent of pressure and inversely proportional to the temperature because these samples have pores as macro unit. However, the hydrogen permeability of the Ni-SCYb composite membrane can be seen to have a confirmed tendency to increase with increasing temperature and pressure. Therefore, the $\mathrm{Ni}-\mathrm{SCYb}$ composite membrane was prepared according to the methods for ceramic membranes, but is expected to have good hydrogen permeation based on solution diffusion, in which density and strength increase with the addition of metal.

Figure 4 shows the hydrogen permeability of the $\mathrm{Ni}-\mathrm{SCYb}$ composite membrane at various temperatures and pressures. Typically, ceramic membranes are known for Knudsen diffusion, which is independent of pressure and inversely proportional to the temperature because these materials have pores as macro units. However, the hydrogen permeability of the Ni-SCYb composite membrane can be confirmed to show a tendency to increase with increasing temperature and pressure. Since these cermet membranes are mixtures of metal and ceramic, the hydrogen permeation mechanism, as well as the solution-diffusion mechanism in accordance with the temperature, changes. Ni-SCYb cermet membranes have dense surface microstructures due to the hot press sintering at high temperature $(1473 \mathrm{~K})$. Accordingly, when experiments were conducted at high temperatures, hydrogen was activated by high temperature and adsorbed slowly on the surface by the interaction between gases [14]. Also, it was believed that this permeability difference came from Fick's first law, in general, according to the following equation: $\mathrm{J}=$ $\mathrm{D}\left(\mathrm{P}_{\mathrm{H}}-\mathrm{P}_{\mathrm{L}}\right) / 1$ (1), where $\mathrm{J}$ is the deuterium flux $\left(\mathrm{mol} \mathrm{m}^{-2} \mathrm{~s}^{-1}\right)$, 


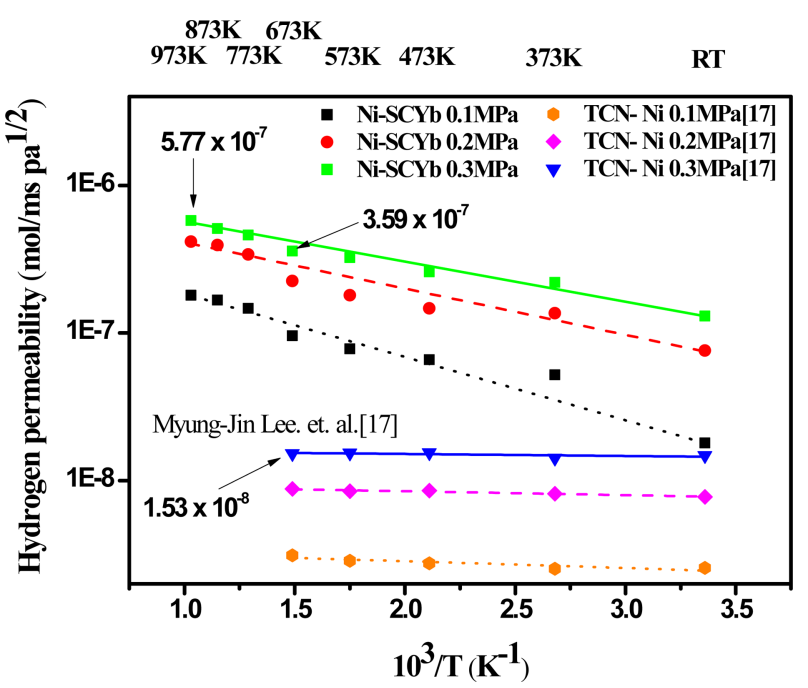

Fig. 4. Hydrogen permeability of $\mathrm{Ni}-\mathrm{SCYb}$ composites membrane by HPS with TCN-20 wt $\% \mathrm{Ni}$ membrane[17] at various temperatures and pressures.

$\mathrm{P}$ is the deuterium concentration of metal $\left(\mathrm{mol} \mathrm{m}^{-3}\right)$, $\mathrm{D}$ is the diffusion coefficient $\left(\mathrm{m}^{2} \mathrm{~s}^{-1}\right), 1$ is the membrane thickness $(\mathrm{m})$ and the $\mathrm{H}$ and $\mathrm{L}$ are high and low part of the membrane. D is expressed as the solubility multiplied by the diffusivity and $\mathrm{P}$ is proportionate to the solubility coefficient and inversely proportionate to membrane thickness [15].

The hydrogen permeability values of the Ni-SCYb composite membrane were $1.8 \times 10^{-7} \mathrm{~mol} / \mathrm{ms} \mathrm{Pa}^{1 / 2}$, $4.16 \times 10^{-7} \mathrm{~mol} / \mathrm{ms} \mathrm{Pa}^{1 / 2}$ and $5.77 \times 10^{-7} \mathrm{~mol} / \mathrm{ms} \mathrm{Pa}^{1 / 2}$ at $973 \mathrm{~K}$ under 0.1-0.3 MPa. These results can be compared with those of other studies; the overall behavior was higher than that of other cermet membranes $\left(\mathrm{Ni}-\mathrm{SCYb} ; 3.59 \times 10^{-7} \mathrm{~mol} / \mathrm{ms} \mathrm{Pa}^{1 / 2}\right.$ at $673 \mathrm{~K}$ under $0.3 \mathrm{MPa}, \mathrm{ACG} / \mathrm{Al} ; 2.62 \times 10^{-7} \mathrm{~mol} / \mathrm{ms}^{P^{1 / 2}}$ at $673 \mathrm{~K}$ under $0.3 \mathrm{MPa}$, TiN-20 wt $\% \mathrm{Co} ; 1.93 \times 10^{-8}$ $\mathrm{mol} / \mathrm{ms} \mathrm{Pa}^{1 / 2} 673 \mathrm{~K}$ under $0.2 \mathrm{MPa}, \mathrm{TiN}-5 \mathrm{wt} \% \mathrm{Ni}$; $3.37 \times 10^{-7} \mathrm{~mol} / \mathrm{ms} \mathrm{Pa}^{1 / 2} 673 \mathrm{~K}$ under $0.2 \mathrm{MPa}, \mathrm{TCN}-20$ wt $\left.\% \mathrm{Ni} ; 1.53 \times 10^{-8} \mathrm{~mol} / \mathrm{ms} \mathrm{Pa}^{1 / 2}\right)$ in a study by N.-R. Lee et al., K.-I. Kim et al. and Myoung-Jin Lee et al. [16-18]. Also, it was higher than that of the PdAg membrane $\left(2.50 \times 10^{-8} \mathrm{~mol} / \mathrm{ms} \mathrm{Pa}^{1 / 2}\right.$ at $\left.573 \mathrm{~K}\right)$ in a study by Y. Zhang et al. [19]. The reaction enthalpy $(\triangle \mathrm{H})$ values according to the pressure were $8.36,7.15$ and $6.16 \mathrm{~kJ} / \mathrm{mol}$ under $0.1 \sim 0.3 \mathrm{MPa}$. These values dropped with grain growth. Outstanding data were found that the membrane after hydrogen permeation had a highly large pore diameter $(17.206 \mathrm{~nm})$. The pore size increased sharply, and it is expected that the pathway widened due to the diffusion of hydrogen.

\section{CONCLUSIONS}

The following conclusions are obtained as a result of the successful synthesis of an Ni-SCYb cermet membrane using sol-gel and ball-milling processes and consequent tests for hydrogen permeability.

Through XRD and SEM analyses, it was confirmed that $\mathrm{SCYb}$ composite was $\mathrm{SCYb}$ with perovskite phase and uniformly distributed synthesis. Also, results of for BET and specific surface area analysis showed reduced with increasing heat treatment temperature; pore volume sharply dropped after hot press sintering. Compared to other samples, average pore diameter after hydrogen permeation increased more than two times due to diffusion of hydrogen.

Hydrogen permeability of the Ni-SCYb composite membrane was $5.77 \times 10^{-7} \mathrm{~mol} / \mathrm{ms} \mathrm{Pa}^{1 / 2}$ at $973 \mathrm{~K}$ under $0.3 \mathrm{MPa}$; this is high permeability compared to other cermet membranes. Also, $\mathrm{SCYb}$ composite and $\mathrm{Ni}$ as catalyst and support had positive impacts on hydrogen permeation.

\section{ACKNOWLEDGEMENTS}

This work was supported by a National Research Foundation of Korea Grant funded by the Korean Government (MEST) (NRF-2009-0093168) and National R\&D Program through the National Research Foundation of Korea (NRF) funded by the Ministry of Science, ITC \& Future Planning (NRF2013M1A7A1A02043993)

\section{REFERENCES}

1. J. Andrews and B. Shabani, Int. Hydrogen Energy 37, 1184 (2012).

2. N. Afgan and A. Veziroglu, Int. Hydrogen Energy 37, 5461 (2012). 
3. M. -H. Jang, S. -H. Park, and T. -W. Hong, Korean J. Met. Mater. 54, 288(2016).

4. E. David and J. Kopac, Int. Hydrogen Energy 36, 4498 (2011).

5. M. D. Dolan, J. Membrane Sci. 363, 12 (2010).

6. J. A. Desai and A. Kumar, Met. Mater. Int. 451-458, 22 (2016).

7. S. Yun and S. Ted Oyama, J. Membrane Sci. 375, 28 (2011).

8. C. Zuo, T. H. Lee, S. E. Dorris, U. Balachandran, and M. Liu, J. Power Sources 159, 1291 (2006).

9. Q. Zhang, Z. Zhu, T. Liu, and W. Liu, J. Membrane Sci. 437, 196 (2013).

10. J. Akedo, Mater. Sci. Forum 449-452, 43 (2004).

11. G. chiodelli, L. Malavasi, C.Tealdi, S. Barison, M. Battagliarin, L. Doubova, M. Fabrizio, C. Mortalo, and R. Gerbasi, J. Alloy. Compd. 470, 477 (2009).

12. J. Akedo, M. Lebedev, A. Iwata, H. Ogiso, and S. Nakano, Mater. Res. Soc. Symp. Proc. 778, 289 (2003).

13. J. Kim, D. Choi, J. Kim, W. Cho, and K. Hwang, Trans. of the Korean Hydrogen and New Energy Society 22, 649
(2011).

14. S. Liu, K. Li, and R. Hughes, Mater. Res. Bull. 39, 119 (2004).

15. L. Yan, W. Sun, L. Bi, S. Fang, Z. Tao, and W. Liu, J. Alloy. Compd. 508, L5-L8 (2010).

16. H. S. Soares, X. Zhang, I. Antunes, J. R. Frade, G. C. Mather, and D. P. Fagg, J. Solid State Chem. 191, 27 (2012).

17. N.-R. Lee, S.-S. Lee, K.-I. Kim, W.-G. Kim, H. Ju, D. M. Kim, and T.-W. Hong, Int. Hydrogen Energy 38, 7654 (2013).

18. K. I. Kim, S. W. Yoo, and T. W. Hong, Trans. Korean Hydrogen New Energy Soc. 21, 264 (2011).

19. M.-J. Lee, Y.-S. Lee, M.-H. Jang, and T.-W. Hong, J. Alloy. Compd. 645, 325 (2015).

20. Y. Zhang, T. Ozaki, M. Komaki, and C. Nishimura, J. Membrane Sci. 224, 81 (2003).

21. H. Iwahara, Y. Asakura, K. Katahira, and M. Tanaka, Solid State Ionics 168, 299 (2004).

22. Q. Zhang, T. Liu, Z. Zhu, L. Hao, and W. Liu, J. Membrane Sci. 415-416, 328 (2012). 